Biochimica et Biophysica Acta, 610 (1980) 221-228

(C) Elsevier/North-Holland Biomedical Press

BBA 99783

\title{
RAPID PURIFICATION OF YEAST MITOCHONDRIAL DNA IN HIGH YIELD
}

MICHAEL E.S. HUDSPETH, DEBORAH S. SHUMARD, KATHLEEN M. TATTI and LAWRENCE I. GROSSMAN

Department of Cellular and Molecular Biology, Division of Biological Sciences, The University of Michigan, Ann Arbor, MI 48109 (U.S.A.)

(Received July 31st, 1979)

(Revised manuscript received July 25 th, 1980)

Key words: mtDNA purification; Buoyant density centrifugation; (S. cerevisiae)

\section{Summary}

A procedure is presented for the rapid isolation of mitochondrial DNA (mtDNA) in high yield from Saccharomyces cerevisiae. Yeast cells, which may be grown to late stationary phase, are broken by a combination of enzymatic and mechanical means; mtDNA is then isolated from a crude mitochondrial lysate by a single cycle of bisbenzimide-CsCl buoyant density centrifugation. mtDNA so isolated is at least $99.5 \%$ pure, and has a mean duplex molecular weight of $24.5 \cdot 10^{6}$. In addition to mtDNA and bulk nuclear DNA, several other yeast nucleic acid species, identified as ribosomal DNA and a mixture of duplex RNAs, form discrete bands in these gradients.

\section{Introduction}

Although 10-15\% of total DNA from the yeast Saccharomyces cerevisiae is mitochondrial, available methods for the isolation of this mitochondrial DNA (mtDNA) do not readily allow the achievement of both high yield and purity. Furthermore, the dual requirement for yield and purity becomes even more difficult under conditions where lesser amounts of mtDNA appear to be present, as in cytoplasmic petite mutants or when cells are not fully derepressed.

We had been isolating mtDNA by the 'handshake' method of Lang et al. [1], in which cells are disrupted by manual agitation with glass beads. We have recently modified that procedure in several ways to increase the speed of the preparation by only minimally purifying mitochondria and using a single cycle of density gradient centrifugation for DNA isolation. Our method, described 
below, allows recovery of an estimated $35-70 \%$ of the mtDNA present in our wild-type strains, even when cells are allowed to grow to late stationary phase.

\section{Materials and Methods}

\section{Yeast strains}

S. cerevisiae strains ID41-6/161 and 13-6 were obtained from P. Perlman, Ohio State University; strains D585-11C and S. carlsbergensis CB12 were from R. Needleman, Wayne State University. Cells were grown to mid-stationary phase in $1 \%$ yeast extract/2\% peptone containing $2 \%$ glucose, or $3 \%$ glycerol plus $2 \%$ ethanol, harvested by centrifugation and washed once with $0.1 \mathrm{M}$ EDTA (pH 7.5).

\section{Formation of spheroplasts}

Cells were resuspended at $2 \mathrm{ml} / \mathrm{g}$ wet weight in $0.1 \mathrm{M} \mathrm{EDTA}(\mathrm{pH} \mathrm{9.0)} / 0.3 \mathrm{M}$ 2-mercaptoethanol and incubated $15 \mathrm{~min}$ at room temperature with moderate agitation ( $200 \mathrm{rev} . / \mathrm{min}$ on a rotary shaker). The cells were then collected by centrifugation, resuspended at the same concentration in $1.0 \mathrm{M}$ sorbitol (Mallinkrodt)/0.1 M EDTA ( $\mathrm{pH} 7.5$ ) containing $1 \mathrm{mg} / \mathrm{g}$ wet weight cells of the lytic enzyme preparation Zymolyase 5000 (Kirin Brewery, Takasaki, Japan), and incubated with rotary agitation for $1 \mathrm{~h}$ at $37^{\circ} \mathrm{C}$. Spheroplasts were then collected by centrifugation.

\section{Mechanical disruption of cells}

$10-20 \mathrm{~g}$ of cells or spheroplasts were suspended in $20-25 \mathrm{ml} 0.9 \mathrm{M}$ sorbitol/ $10 \mathrm{mM}$ EDTA/0.1 M Tris-HCl ( $\mathrm{pH}$ 7.5)/0.1\% bovine serum albumin (breakage buffer) in $250-\mathrm{ml}$ flat-bottom centrifuge bottles and chilled to $4^{\circ} \mathrm{C}$. All subsequent operations prior to lysis of the mitochondrial pellet were carried out at $4^{\circ} \mathrm{C}$. Cold, dry, acid-washed $0.5 \mathrm{~mm}$ glass beads $(100-150 \mathrm{~g})$ were added and the cells disrupted by vigorous manual agitation essentially according to the 'handshake' procedure [1]. More than 90\% of cells appeared as ghosts after 2-3 min, as monitored by phase contrast microscopy. The liquid was decanted and the beads rinsed with five 50-ml portions of breakage buffer. The supernatants were combined and centrifuged $10 \mathrm{~min}$ at $1500 \times \mathrm{g}$ to pellet the nuclei and cell debris. The supernatant was then centrifuged $20 \mathrm{~min}$ at $15000 \times \mathrm{g}$ to pellet the mitochondria, which were resuspended in $150 \mathrm{ml} 0.9 \mathrm{M}$ sorbitol/10 $\mathrm{mM}$ Tris- $\mathrm{HCl}(\mathrm{pH} 7.5) / 2 \mathrm{mM}$ EDTA, and repelleted at $20000 \times \mathrm{g}$ for $20 \mathrm{~min}$. The last pellet was well drained to remove sorbitol, which causes background fluorescence in bisbenzimide-CsCl gradients.

\section{Buoyant centrifugation of mitochondrial DNA in bisbenzimide-CsCl gradients}

Mitochondrial pellets from $20-30 \mathrm{~g}$ cells were resuspended in $7.5 \mathrm{ml} 10 \mathrm{mM}$ Tris- $\mathrm{HCl}$ ( $\mathrm{pH} 8.2$ )/10 mM EDTA/100 mM NaCl, brought to $2 \%$ Sarkosyl and lysed for $2 \mathrm{~h}$ at room temperature before addition of $1.26 \mathrm{~g} \mathrm{CsCl}$ per ml lysate. Alternatively, lysis was carried out for $1 \mathrm{~h}$ at room temperature, solid $\mathrm{CsCl}$ added as above, and lysis allowed to continue overnight at $4^{\circ} \mathrm{C}$. Bulk protein was removed as a top pad after centrifugation for $1-2 \mathrm{~h}$ at $80000 \times \mathrm{g}$ at $20^{\circ} \mathrm{C}$ in the Spinco 65 rotor. The remainder of the lysate was brought to $100 \mu \mathrm{g} / \mathrm{ml}$ 
bisbenzimide (Hoechst 33258; Aldrich Chemical Co. or American Hoechst) and the density adjusted to $1.693 \mathrm{~g} / \mathrm{ml}$. Centrifugation was then continued for 18$20 \mathrm{~h}$ at $90000 \times \mathrm{g}$. After centrifugation, the fluorescent mtDNA band was removed under long-wave ultraviolet illumination.

For preparations from more than 11 of culture we found it convenient to deproteinize the lysate, precipitate the DNA from $0.3 \mathrm{M}$ sodium acetate with 2 vols. ethanol and redissolve the DNA in $15 \mathrm{ml} 10 \mathrm{mM}$ Tris- $\mathrm{HCl}(\mathrm{pH} 7.5) / 20 \mathrm{mM}$ $\mathrm{NaCl} / 1 \mathrm{mM}$ EDTA. This concentration step allowed centrifugation of the DNA from up to 161 of culture in a single $20 \mathrm{ml}$ gradient in the Spinco 50.2 rotor, and eliminated the need to centrifuge lysates prior to adding bisbenzimide. Lysates were deproteinized once with phenol : chloroform : isoamyl alcohol (25: $24: 1)$ and once with chloroform.

The dye was largely removed by $4-5$ extractions with CsCl-saturated isopropanol and the DNA solution dialyzed prior to ethanol precipitation. mtDNA from as little as $5 \mathrm{~g}$ of cells could be spooled out of a $67 \%$ ethanol solution if desired. We note that bisbenzimide is added after $\mathrm{CsCl}$ because addition of the concentrated dye solution to DNA in low ionic strength buffers caused a DNAdye precipitate to form which was not readily redissolved.

\section{Results}

\section{Effect of Zymolyase on mitochondrial DNA yield}

The effect of Zymolyase treatment on the yield of mtDNA from wild-type strain ID41-6/161 was investigated. Two $5 \mathrm{~g}$ portions of stationary phase cells were broken either with glass beads alone or following treatment with Zymolyase; in either case, breakage was over $90 \%$, as monitored by microscopy. The fractionation pattern of each lysate after centrifugation to equilibrium in $\mathrm{CsCl}$ (Fig. 1) shows that Zymolyase treatment increased mtDNA yield nearly 3-fold; the recovery of nuclear DNA was equal to within $15 \%$.

The unequal yields of mtDNA occurred despite the nearly quantitative levels of cell breakage, which were independent of whether or not Zymolyase was used. This result shows that the ability of bodies with the visual appearance of ghosts to release mitochondria need not be equal, and that Zymolyase treatment enhances the leakiness of ghosts. Indeed, we observed directly the presence of a strikingly higher density of cytoplasmic material in samples broken after enzyme treatment compared with samples broken with glass beads alone.

\section{The use of bisbenzimide-CsCl gradients}

Bisbenzimide forms a complex with duplex DNA which can undergo induced fluorescence and which has a lower buoyant density than DNA alone. In addition, the binding reaction appears to require three adjacent A-T base pairs [2], making bisbenzimide a useful reagent to enhance base-composition-dependent buoyant density separations $[3,4]$. We took advantage of these properties of bisbenzimide to improve the isolation of mtDNA.

We assayed the yield of yeast mtDNA using bisbenzimide gradients with the two methods for cell breakage described in the preceeding section. Cells broken either with glass beads alone or after Zymolyase treatment were processed as described in Materials and Methods and centrifuged to equilibrium in $\mathrm{CsCl}$ gra- 

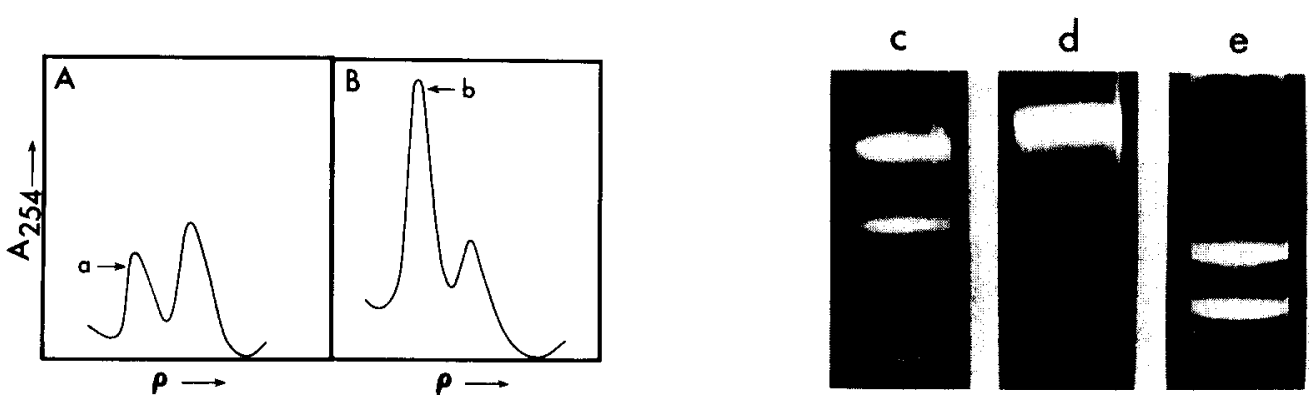

Fig. 1. Increase in mtDNA yield by Zymolyase treatment. Stationary phase wild-type cells (2.5 g) were broken as described in Materials and Methods without (A) or with (B) Zymolyase pretreatment. Portions of each preparation were centrifuged to equilibrium in dye-free CsCl gradients. The figure shows ultraviolet absorbance traces of the fractionated gradients. Portions of the mtDNA bands labelled $a$ and $b$ were used for the analogously labelled slots in Fig. 4.

Fig. 2. Ultraviolet fluorescence photographs of bisbenzimide-CsCl and CsCl-diaminophenylindole gradients of yeast DNA. Portions of the extracts described in the legend to Fig. 1 were centrifuged to equilibrium in $10 \mathrm{ml} \mathrm{CsCl}$ gradients containing $150 \mu \mathrm{g} / \mathrm{ml}$ bisbenzimide (c and d) or $250 \mu \mathrm{g} / \mathrm{ml}$ diaminophenylindole (e). (c), extract from cells broken without Zymolyase pretreatment; (d), with pretreatment; (e), a separately prepared extract to illustrate the $30 \%$ smaller separation between nuclear and mitochondrial DNAs when diaminophenylindole is used. Portions of the mtDNA bands from $c$ and $d$ were used for the analogously labelled slots in Fig. 4.

dients containing $150 \mu \mathrm{g} / \mathrm{ml}$ bisbenzimide. Ultraviolet fluorescence photographs of the gradients are shown in Fig. 2. The increased yield of mtDNA when Zymolyase treatment precedes cell breakage, documented in the dye-free gradients in Fig. 1, is visually apparent (Fig. 2, c vs. d). The separation between the nuclear and mitochondrial DNA band centers is $1.6 \mathrm{~cm}$. This separation is compared with that given by 4',6-diamino-2-phenylindole (Fig. 2, tube e), another fluorescent dye in common use for preparing yeast mtDNA [5]. The separation between the nuclear and mitochondrial DNA bands in the diaminophenylindole- $\mathrm{CsCl}$ gradient is about $1 \mathrm{~cm}$. The use of bisbenzimide-CsCl gradients allows purification of mtDNA in a single cycle of centrifugation which contains less than $0.5 \%$ contamination with nuclear DNA (see below).

A minor band is visible in the bisbenzimide- $\mathrm{CsCl}$ gradient (Fig. 2, tube c) below nuclear DNA. This band was identified by Petes et al. [6] as containing ribosomal DNA sequences. We have confirmed (data not shown) that our minor band is enriched for the EcoRI-generated restriction pattern reported for ribosomal DNA [7].

In addition, a second minor band is visible below the ribosomal DNA band in some gradients (data not shown). This material is sensitive to RNAase but not DNAase, and migrates in $1 \%$ agarose gels as three sharp bands of molecular weights $1.2 \cdot 10^{6}, 2.7 \cdot 10^{6}$ and $3.2 \cdot 10^{6}$, based on duplex DNA standards. Thus, we conclude provisionally that the gradient species consist of the duplex RNAs found in yeast cells, some of which are associated with the 'killer' phenotype $[8,9]$.

\section{Properties of the isolated $m t D N A$}

The purity of mtDNA was assayed by bisbenzimide-CsCl centrifugation. The lower limit of detection in photographs in a tube of $1.25 \mathrm{~cm}$ diameter was 
A

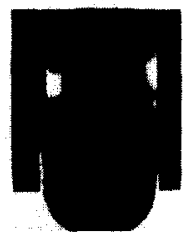

B

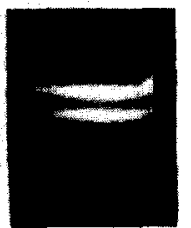

C

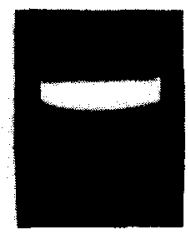

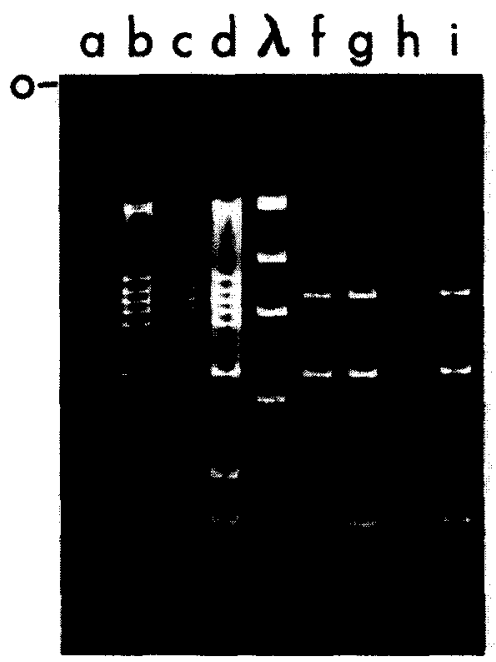

Fig. 3. Purity of $\mathrm{mtDN}$ A preparations evaluated by bisbenzimide-CsCl gradients. Ultraviolet fluorescence photographs of gradients generated in the Spinco SW 50.1 rotor, $36000 \mathrm{rev} . / \mathrm{min}, 20^{\circ} \mathrm{C}, 22 \mathrm{~h} . \mathrm{A}, 0.46 \mu \mathrm{g}$ yeast nuclear DNA; B, $10 \mu \mathrm{g}$ each of nuclear and mitochondrial DNAs; C, $92 \mu \mathrm{g}$ mtDNA. Photographs on Kodak Royal X-Pan film of tubes illuminated with long-wave ultraviolet light were made through a Wratten No. 9 (yellow) filter.

Fig. 4. Electrophoresis of restriction endonuclease digests. mtDNA was digested with HincII (New England Biolabs.) for $30 \mathrm{~min}, 37^{\circ} \mathrm{C}$ in $10 \mathrm{mM}$ Tris- $\mathrm{HCl}(\mathrm{pH} 7.9) / 7 \mathrm{mM} \mathrm{MgCl} / 60 \mathrm{mM} \mathrm{NaCl} / 6 \mathrm{mM} \mathrm{2-mercap-}$ toethanol, electrophoresed in a $1 \%$ agarose gel (type $\mathrm{ME}$, Seakem) at $35 \mathrm{~V}$ for $15 \mathrm{~h}$, and stained with ethidium bromide. Lanes $a-d$ show DNA from strain ID41-6/161 in the order: -Zymolyase, - bisbenzimide; +Zymolyase, bisbenzimide; -Zymolyase, +bisbenzimide; + Zymolyase, +bisbenzimide. DNA from strain 13-6 is shown in lanes $f-i$ in the same sequence. Lane $\lambda$ is bacteriophage $\lambda$ DNA restricted with HindIII. Each mtDNA lane contains 1\% of its preparation except a and $f$, which contain 2 and $4 \%$, respectively.

determined with yeast nuclear DNA to be below $0.46 \mu \mathrm{g}$ (Fig. 3A). Detection of $0.2 \mu \mathrm{g}$ is possible by visual inspection of gradient tubes.

Tube B shows a mixture of $10 \mu \mathrm{g}$ each of nuclear and mitochondrial DNAs. The species readily resolve under the conditions of centrifugation (SW 50.1 rotor, $36000 \mathrm{rev} . / \mathrm{min}, 22 \mathrm{~h}$ ), although the band centers are separated by only $3 \mathrm{~mm}$, compared to $16 \mathrm{~mm}$ in the 65 angle rotor. When a gradient is overloaded with $92 \mu \mathrm{g}$ of mtDNA, no contamination with nuclear DNA is visible (tube C), giving a calculated upper limit of contamination of $0.25 \%$. By contrast, both nuclear and mitochondrial DNA bands isolated from a single cycle of dye-free $\mathrm{CsCl}$ centrifugation and similarly assayed are significantly cross-contaminated (data not shown).

The molecular weight of wild-type mtDNA was estimated by analysis of restriction endonuclease digests and by electrophoresis of undigested DNA through $0.5 \%$ agarose gels at a low field strength. Fig. 4 shows restriction patterns generated by HincII on wild-type (slots a-d) and petite (slots $\mathrm{f}-\mathrm{i}$ ) mtDNA. The latter is from an analogous isolation carried out with strain 13-6, a petite derived from ID41-6/161; the petite mtDNA has a repeat molecular weight of $8.8 \cdot 10^{6}$ and consists of HincII bands 8,10 and portions of 5 and 7 of the wild-type map [10]. Each slot contains $1 \%$ of the total mtDNA recovered from $9.4 \cdot 10^{10}$ cells except slot a, which contains $2 \%$, and slot $f$, 
which contains $4 \%$. By this criterion, the molecular weight is adequate to produce the largest HincII fragment $\left(M_{\mathbf{r}}=15 \cdot 10^{6}\right)$ in approximately molar yield. Undigested mtDNA migrated in a $0.5 \%$ agarose gel as a disperse band with two thirds of the mass falling between molecular weights of $20.7 \cdot 10^{6}$ and $29 \cdot 10^{6}$ (data not shown).

\section{Yield of $m t D N A$}

Total mtDN.A yields for several yeast strains are summarized in Table I. The mtDNA isolated by using Zymolyase and dye-CsCl gradients with glucosegrown ID41-6/161 has been normalized to 100. Omission of Zymolyase reduced the recovery to $42 \%$, consistent with the dye-free gradient patterns shown in Fig. 1.

Recoveries were always significantly lower when mtDNA was isolated from dye-free $\mathrm{CsCl}$ gradients. For instance, for cells broken by the Zymolyase-glass bead procedure, 3 -fold more mtDNA was recovered from dye-CsCl gradients than from dye-free gradients (Table I, line 2 vs. line 4 ). Since equal amounts of DNA were added to each gradient, the difference in yield necessarily reflects the number of gradient fractions which can be pooled while minimizing nuclear DNA contamination. mtDNA recovered from dye-free gradients was significantly contaminated with nuclear DNA, despite conservative pooling of fractions to take the least-dense one-third of the peak. The remainder of the table entries, therefore, compare only the effects of Zymolyase treatment as assayed by dye-CsCl gradients.

A similar enhancement of recovery is seen for an independent wild-type strain grown with glucose, D585-11C, and for the petite strain, 13-6. When strain ID41-6/161 was grown with glycerol and ethanol as the carbon sources, in place of glucose, the enhancement of recovery with Zymolyase treatment

\section{TABLE I}

\section{YIELDS OF MITOCHONDRIAL DNA}

Yields were determined chemically using a diphenylamine assay [18]. The isolation parameters indicate variations from the basic 'handshake' isolation procedure [1] of mechanical breakage followed by CsCl density gradient centrifugation. Yield is given in $\mu \mathrm{g} /$ cell $\left(X 10^{9}\right)$. Each value is the mean of at least two determinations. The recovery of mtDNA from glucose-grown ID41-6/161 by the use of Zymolyase and dye-CsCl gradients is taken as 100 .

\begin{tabular}{llll}
\hline Strain & Isolation parameters & Yield & Relative recovery \\
\hline ID41-6/161* & 'handshake' & 0.3 & 25 \\
& +Zymolyase & 0.4 & 33 \\
& +dye-CsCl & 0.5 & 42 \\
& +Zymolase, +dye-CsCl & 1.2 & 100 \\
D585-11C* & +dye-CsCl & 0.3 & 25 \\
& +Zymolyase, +dye-CsCl & 1.1 & 92 \\
$13-6 *$ & +dye-CsCl & 0.4 & 33 \\
ID41-6/161** & +Zymolyase, +dye-CsCl & 0.9 & 75 \\
& +dye-CsCl & 0.7 & 58 \\
\hline
\end{tabular}

* Grown with $2 \%$ glucose as carbon source.

** Grown with $2 \%$ ethanol $/ 3 \%$ gly cerol as carbon sources. 
was only 1.6 -fold, although the maximum recovery was not significantly different from that found when glucose was used as a carbon source (see Discussion). We note that all cells were harvested in stationary phase.

\section{Discussion}

We have presented a method for isolating yeast mitochondrial DNA rapidly and in high yield. This method improves the yield and purity of mtDNA for two reasons: (1) Zymolyase treatment of yeast cells before mechanical breakage with glass beads increases the amount of cytoplasmic material released by the cells; and (2) enhancement of the buoyant density separation in CsCl between nuclear and mitochondrial DNAs with the dye bisbenzimide allows virtually all of the mtDNA present to be recovered from the gradient. Such DNA is routinely at least $99.5 \%$ free of nuclear DNA.

Yields of mtDNA are seen from the data in Table I to be improved 3.7-4.0fold for wild-type $S$. cerevisiae cells by the introduction of Zymolyase treatment and dye-CsCl centrifugation. In addition to the strains listed, we applied this method to $S$. carlsbergensis CB12. The Zymolyase plus dye-CsCl method increased the yield 5-fold, but the maximum yield was significantly lower than that observed for $S$. cerevisiae strains (data not shown). We have not investigated the reasons for this difference.

Calculation of absolute recoveries depends on knowing the amount of mtDNA per cell. The amount of mtDNA in petite strains has not been well studied. For wild-type strains, a value of $1.7 \cdot 10^{-9} \mu \mathrm{g}$ mtDNA per cell can be calculated from the value $10^{10}$ daltons DNA per haploid nucleus $[11,12]$, assuming that $10 \%$ of the total DNA is mitochondrial and that the amount of nuclear DNA does not vary during the cell cycle. Based on this value, recoveries from the wild-type $S$. cerevisiae strains using the Zymolyase plus dye-CsCl method ranged from 66 to $72 \%$.

The cellular fraction of mtDNA, however, is known to depend on strain, carbon source and growth phase (reviewed in Ref. 13). For instance, Goldthwaite et al. [14] showed that the fraction of mtDNA in their haploid strain ranged from 2.2 to $36.6 \%$ when the carbon source and growth phase were varied; early stationary phase cells contained $16 \%$ mtDNA when grown with $1.5 \%$ glucose and $33 \%$ when grown with $3 \%$ glycerol. Their strain, 20BB, appears to be the most repressible assayed for mtDNA content [13]. Nagley and Linnane [15], using an independent diploid strain, found identical fractions of mtDNA (17$18 \%$ ) in early stationary cells when the carbon source was either glucose or ethanol. Based on our recoveries, mtDNA content of strain ID41-6/161 is similarly unaffected by glucose repression. Since the actual fraction of mtDNA in our cells at the time of harvest is unknown, we can only estimate our absolute recoveries to be in the range $35-70 \%$, based on typical values of $10-20 \%$ mtDNA in glucose-grown stationary phase cells.

We previously used distamycin A to enhance buoyant separations of DNA in $\mathrm{CsCl}$ gradients [16]. Bisbenzimide provides approximately the same enhancement of base-composition-dependent separation with the added convenience that DNA bands are visible under ultraviolet excitation; its use for preparing mouse satellite [3] and trypanosome [4] DNA has been reported. 
We no longer specifically remove bisbenzimide from our mtDNA preparations. DNA containing bound bisbenzimide can be digested to completion by the twenty restriction endonucleases we have used, presumably reflecting the binding specificity of the dye for stretches of $d(A-T)$ [2]. We have not detected unusual migration of restriction fragments containing bound dye by electrophoresis through either agarose or acrylamide gels, although slightly retarded migration of selected fragments has been reported [17]. In addition, DNA containing bound bisbenzimide can be used for transforming Escherichia coli and for nucleotide sequencing by either chemical or enzymatic methods (data not shown).

We have been unable to detect mtDNA in the DNA purified from our nuclear pellet and estimate that no more than $0.03 \%$ contamination with mtDNA could have been present. This finding is consistent with the high yields of mtDNA we have obtained, and offers an alternative to generating rho $0^{\circ}$ mutants as a source of nuclear DNA of high purity.

\section{Acknowledgements}

We thank Drs. Philip Perlman and Richard Needleman for providing yeast strains, Carol Jacobson and Deborah Dietrich for typing the manuscript, and David Bay for photographic work. This work was supported by grant GM26546 from the National Institutes of Health.

\section{References}

1 Lang, B., Burger, G., Doxiadis, I., Thomas, D.Y., Bandlow, W. and Kaudewitz, F. (1977) Anal. Biochem. 77, 110-121

2 Muller, W. and Gautier, F. (1975) Eur. J. Biochem. 54, 385-394

3 Manuelidis, L. (1977) Anal. Biochem. 78, 561-568

4 Simpson, L. (1979) Proc. Natl. Acad. Sci. U.S.A. 76, 1585-1588

5 Williamson, D.H. and Fennell, D.J. (1975) in Methods in Cell Biology (Prescott, D.M., ed.), Vol. XII, pp. 335-351, Academic Press, New York

6 Petes, T.D., Hereford, L.M. and Botstein, D. (1977) Cold Spring Harbor Symp. Quant. Biol. XLII, 1201-1207

7 Cramer, J.H., Farrelly, F.W. and Rownd, R.H. (1976) Molec. Gen. Genet. 148, 233-241

8 Wickner, R.B. and Leibowitz, M.J. (1976) J. Mol. Biol. 105, 427-434

9 Bruenn, J. and Kane, W. (1978) J. Virol. 26, 762-772

10 Mahler, H.R., Hanson, D., Millex, D., Bilinski, T., Ellis, D.M., Alexander, N.J. and Perlman, P.S. (1977) in Mitochondria 1977 (Bandlow, W., Schweyen, R.J., Wolf, K. and Kaudewitz, F., eds.), pp. 345-370, de Gruyter, Berlin

11 Hartwell, L. (1970) Ann. Rev. Gen. 4, 373-396

12 Bicknell, J.N. and Douglas, H.C. (1970) J. Bacteriol. 101, 505-512

13 Williamson, D.H., Johnston, L.H., Richmond, K.M.V. and Game, J.C. (1977) in Mitochondria 1977 (Bandlow, W., Schweyen, R.J., Wolf, K. and Kaudewitz, F., eds.), pp. 1-24, de Gruyter, Berlin

14 Goldthwaite, C., Cryer, D.R. and Marmur, J. (1974) Molec. Gen. Genet. 133, 87-104

15 Nagley, P. and Linnane, A.W. (1972) Cell Diff. 1, 143-148

16 Tatti, K.M., Hudspeth, M.E.S., Johnson, P.H. and Grossman, L.I. (1978) Anal. Biochem. 89, 561-571

17 Loucks, E., Chaconas, G., Blakesley, R.W., Wells, R.D. and van de Sande, J.H. (1979) Nucl. Acids Res. $6,1869-1879$

18 Giles, K.w. and Myers, A. (1965) Nature 206, 93 